\title{
ACCEPTANCE AND USAGE OF EXTENSIBLE BUSINESS REPORTING LANGUAGE: AN EMPIRICAL REVIEW
}

\author{
${ }^{1}$ Elissavet Stergiaki, ${ }^{1}$ Antonios Stavropoulos and ${ }^{2}$ Theodora Lalou \\ ${ }^{1}$ Department of Applied Informatics, Faculty of Accounting Information Systems, \\ University of Macedonia, Egnatia 156, P.O. Box 1591, 540 06, Thessaloniki, Greece \\ ${ }^{2}$ Department of Accounting and Finance, Business School, Faculty of Financial Information Systems, \\ University of Greenwich, Greenwich Campus, Old Royal Naval College, Park Row, SE109LS, London
}

Received 2012-11-08, Revised 2013-03-14; Accepted 2013-04-29

\begin{abstract}
Extensible Business Reporting Language (XBRL) is a language based on XML that provides an effective solution for the preparation, presentation and exchange of International Financial Reporting Standards. Many researchers examined the adoption, acceptance or usage of XBRL but none have clarified a direct link between the acceptance of technology and how it affects XBRL users. So, a significant issue to answer is: What is the level of acceptance of XBRL in the European region? Particularly, a new acceptance model was developed based on Technology Acceptance Model 2 (TAM2) in order to test XBRL usage and its impact with five major constructs. The sample consists of 100 listed companies from European Union countries such as United Kingdom, Germany, Spain, Italy, France, Denmark, The Netherlands, Switzerland, Belgium, Luxemburg and Poland. The results reveal that a great number of companies in the European Union are satisfied with the output and the perspectives of XBRL acceptance and usage. The above argument is supported by the positive correlation found in this research among independent constructs and the dependent factors of XBRL acceptance and usage. Europe appears to be a strong supporter of XBRL technology, so non adopters of XBRL can use the results of this study and decide whether XBRL is a useful tool for them or not.
\end{abstract}

Keywords: XBRL, TAM2, Europe and XBRL Usage

\section{INTRODUCTION}

In the age of digitalization, business information plays the most significant role for information specialists in the entire world. Information specialists are looking for new revolutionary tools, tools that can load specific information directly into information systems using the World-Wide-Web. One such tool is XBRL, which is an XML-based technology for the creation, preparation, exchange and publication of financial information (Graning et al., 2011). The use of a standardized tool, such as XBRL, would help companies to display data across all software applications, due to its compatibility with other software, without the need of retyping any parts of it (Blanas et al., 2011). XBRL has the potential to help organizations and agencies to improve their internal and external financial data flows and, most significant, to improve the communication between companies. XBRL has been stressed in the literature, as an innovation promising to change the way financial information is produced and consumed (Doolin and Troshani, 2007).

According to Locke and Lowe (2007) the success of projects such as XBRL is being measured by the spread of adoption in many countries and identifies the most important factors that influence its acceptance. Previous studies that investigate the adoption of XBRL in different countries indicate that XBRL adoption has a positive impact on professional and non-professional financial users (Hodge et al., 2004; Pinsker, 2008). Therefore, in order to decide whether XBRL is a successful Corresponding Author: Elissavet Stergiaki, Department of Applied Informatics, Faculty of Accounting Information Systems, University of Macedonia, Egnatia 156, P.O. Box 1591, 540 06, Thessaloniki, Greece 
technological innovation we have to examine the degree of its acceptance and usage. Since, XBRL is a new technology at an early stage, there are limited studies surrounding its adoption or usage by firms worldwide. Previous studies tried to examine contexts related to either the adoption or usage of XBRL without providing a thorough comprehension of the two important components of XBRL technology: acceptance and usage. For that reason, this study attempts to measure the infiltration of XBRL in Europe and the factors that influence its acceptance and usage.

System acceptance can be considered as the way people evaluate and use the technology (Hossain and De Silva, 2009). Therefore, system acceptance and usage is increasingly viewed as an important component for the examination of Information System (IS) success. One of the most well-known models used in the context of IS for the study of a new technology and its acceptance, is Technology Acceptance Model (TAM). Hence, this study examines XBRL acceptance and usage by proposing a model based on TAM2, which is an extension of TAM. The proposed model consists of determinants such as the Perceived Usefulness, Ease of Use, Output Quality, Training Costs and Intention to Use.

The following section provides a brief literature review of XBRL, XBRL adoption-usage and TAM models. Section 3 explains the research model, the hypotheses and the research design. Section 4 reports the results of the study and finally, Section 5 presents the conclusions.

\subsection{Literature Review}

\subsubsection{XBRL}

XBRL stands for extensible Business Reporting Language and it is an extension of the extensible Markup Language (XML), which in turn is an evolution of the Hyper Text Markup Language (HTML). XBRL is a royalty-free, open standard that enables more rapid and efficient processing of information within and across companies (Arnold et al., 2012) and therefore can be used to accommodate electronically prepared financial statements and reports globally (Saeedi et al., 2005). XBRL does not generate accounting standards but promotes their usability: an organization can utilize it, in order to define financial information and generate financial reports in various formats. Technically, the main corpus of XBRL is XBRL taxonomy. A financial reporting taxonomy acts like a dictionary of accounts with specified relations between them. For instance, in an accounting taxonomy, cash is being classified as a subset of current assets and, in turn, current assets are classified as a subset of total assets. Additionally, the taxonomy can be extended with more elements thanks to the extensibility of the language (Valentinetti and Rea, 2011). After the taxonomy has been designed and reviewed, it can be mapped to an instance document. Then, the instance report easily becomes a financial report presented in a variety of formats. Standardization in XBRL can assimilate information from many organizations and promote effectiveness (Locke and Lowe, 2007), as it is a language that allows the electronic exchange of business reports and eliminates the difficulties of current financial reporting (Weber, 2003). Finally, XBRL is considered to be a useful global development among accountants, investors, regulators and organizations and is already adopted by many entities such as accounting offices, financial institutions, governmental organizations and software vendors.

\subsection{XBRL Adoption and Usage in Europe}

XBRL becomes more widely accepted mainly because European regulators, agencies and companies are genuinely interested in accepting and implementing technological innovation or because they are expecting their governments to set strict regulations for the financial world (Buys, 2008). However, XBRL adoption rate in Europe is accelerating, mostly because of the convergence of International Financial Reporting Standards (IFRS). The European Union strongly supports the IFRS-XBRL connection (Bonson et al., 2009). Several researchers have provided insight into the adoption, acceptance or usage of XBRL but to the best of our knowledge, there is no clarification regarding a direct link between the usage of technology and how it affects stakeholders to address data-production. Most of these studies examine either the adoption or usage and are based on a small number of involved users (Hodge et al., 2004; Pinsker, 2008). Premuroso and Bhattacharya (2007), examined the major factors for the great penetration rate of XBRL among organizations and found them to be liquidity, corporate governance, firm size, auditor type and company performance. Doolin and Troshani (2007) studied the organizational adoption of XBRL in Australian entities using the Technology Organization Environment (TOE) framework and concluded that innovation champion and organizational readiness, relative advantage, complexity, observability and stability, market conditions, trading partner influence, available information, critical mass and available support are the most important factors that affect XBRL adoption. Moreover, Pinsker (2008) tested competing theories from a previous Pinscher's research framework to provide a better understanding of XBRL 
adoption intentions of managers who have low knowledge of XBRL, but work for firms who may adopt it. Technology Acceptance Model (TAM) and Absorptive Capacity were used for the examination of three major variables: perceived usefulness, favorable attitude and absorptive capacity. The results indicated that perceived usefulness and absorptive capacity have a significant influence on user attitudes toward XBRL adoption. Ghani and Jusoff (2009), comparing XBRL, PDF and HTML, observed that decision accuracy and cognitive effort are important factors that affect user's opinion regarding the adaptation of the desirable presentation format. Felden (2011) developed a theoretical model based on Technology Acceptance Model (TAM) and Institutional Theory (InT) in an order to examine the XBRL adoption level and its impact parameters in Germany. The results of the study showed that the advantages of XBRL usage do not provide a reason to adopt it. Henderson et al. (2012) investigated XBRL adoption for both internal and inter-organizational purposes using technological, organizational and environmental factors and found a significant impact on internal adoption.

\subsection{Technology Acceptance Model}

The adoption, acceptance and usage of a new technology have proven to be one of the major interests of researchers until now. For years, many academics tried to develop the most appropriate and precise model that examines the acceptance of a new technology in an organization. Finally, synthesizing prior frameworks on technology acceptance model, Davis (1989) proposed TAM. Technology Acceptance Model (TAM) is one of the most utilized models of information systems acceptance (Basoglou et al., 2007). Furthermore, Venkatesh and Davis (2000) proposed the TAM2 in order to examine the social influence in technology acceptance. The goal of TAM2 is to maintain the initial TAM constructs, present new additions regarding constructs that are linked to the acceptance of an Information System (IS) and fill the gaps of the original model TAM. Additionally, it adds new constructs and focuses on the acceptance of a target system providing a clearer picture of the factors that affect it. As Venkatesh and Davis (2000) states "TAM2 consists of further key factors of TAM's perceived usefulness and usage constructs to understand the correlation of these factors with the amount of user experience of the system". The structure of TAM2 has proven to be the most appropriate and it has been used in different kind of areas (Venkatesh and Davis, 2000). TAM2 has been used by many practitioners in order to examine internet acceptance
(Abbasi et al., 2011; Castaneda et al., 2009), ERP acceptance (Youngberg et al., 2009) and disclosure technology adoption intentions using XBRL (Pinsker, 2008) which indicates that TAM2 is the most suitable model for the examination of XBRL acceptanceusage in Europe.

\section{MATERIALS AND METHODS}

\subsection{Research Methodology}

This study uses the TAM2, as the foundation model to examine the factors that lead to XBRL usage. The proposed model consists of five key constructs, which are: Perceived Usefulness (PU), Perceived Ease Of Use (PEOU), Output Quality (OQ), Training Costs (TC) and Behavioral Intention (BI). Perceived Usefulness (PU) in TAM and TAM2 is a direct construct of behavior intention and it is used as a core determinant. PU in TAM and TAM2 is a direct construct of BI and it is used as a core determinant. PU is a significant factor that affects user acceptance of IS (Davis, 1989). Previous studies prove that PU has a significant effect on IS acceptance and usage (Davis, 1989; Wang and Strong, 1996). PU is defined as: "The degree to which a person believes that using a particular system would enhance his or her job performance". However, several researchers found that BI and usage behavior have a significant relationship (Davis, 1989; Dishaw and Strong, 1999; Venkatesh and Davis, 2000; Chen et al., 2002; Venkatesh et al., 2003). BI is defined as: "The degree to which a person has formulated conscious plans to perform or not perform some specified future behavior" (Venkatesh and Davis, 2000). Therefore, we assume that PU will have a significant impact on BI regarding the usage of XBRL. Thus, the first hypothesis is:

\section{Hypothesis 1}

Perceived Usefulness (PU) has a positive effect on user's Intention (BI) to use XBRL.

PEOU is also a direct determinant of BI in TAM and TAM2. PEOU is defined as: "The degree to which a person believes that using a particular system would be free of effort" (Davis 1989). PEOU is key factor that affects IS acceptance, either directly through BI or indirectly through PU (Davis, 1989). Venkatesh and Davis (2000) mention that PEOU has significant direct effect on user acceptance of IS. Consequently, if XBRL is easy to use, users are more likely to have higher intention to accept it. So, the second and third hypotheses are: 


\section{Hypothesis 2}

Perceived Ease Of Use (PEOU) has a positive effect on user's Intention (BI) to use XBRL.

\section{Hypothesis 3}

Perceived Ease Of Use (PEOU) has a positive effect on user's Perceived Usefulness (PU) of XBRL.

XBRL training is considered one of the most important factors that lead to greater XBRL adoption and user acceptance (Hill and Troshani, 2007). If there is no training available, XBRL adoption will be slow. Therefore, in this study, Training Costs (TC) closely affect the intention to use XBRL. So, it is assumed that the lower the training costs are, the more significant the degree of behavior intention to use XBRL will be.

\section{Hypothesis 4}

Lower Training Costs (TC) have a positive effect on user's intention (BI) to use XBRL.

$\mathrm{OQ}$ is a factor which is linked to PU, firstly introduced in TAM2 by Venkatesh and Davis (2000). It is defined as: "The degree to which an individual believes that the system performs the job tasks well" (Venkatesh and Davis, 2000). It measures the success of a system in meeting all the requirements. Moreover, most users perceive system usefulness by taking into consideration what job tasks a system is capable of doing and how well the system completes these tasks. Furthermore, the potential impacts of XBRL on the quality of financial information are determined through consistency and comparability, reliability and accessibility, relevance, decision usefulness and transparency of the system (Baldwin et al., 2006). Hence we proposed the fifth hypothesis.

\section{Hypothesis 5}

Output Quality (OQ) has a positive effect on user's Perceived Usefulness (PU) of XBRL.

\subsection{Research Design}

The main purpose of this study is to examine the factors that lead to the acceptance and usage of XBRL across several European countries. United Kingdom, Germany, Spain, Italy, France, Denmark, The Netherlands, Switzerland, Belgium, Luxemburg and Poland are the countries represented in the sample with at least one company based in them. The research target firms were listed companies that have implemented XBRL technology in Europe. The data were collected using an on-line questionnaire survey. The on-line questionnaire survey consisted of two parts. The first part documented the participant's demographic information. The second part documented the participant's observation of each variable in the model. The demographic variables assessed were gender, age, level of education, work experience, frequency of using XBRL technology and the degree of familiarity with using online services. The second part indicates the degree of participant's agreement with each construct. A 5-point Likert scale was used to measure the nondemographic questions with values varying from (1) "strongly disagree" to (5) "strongly agree". The neutral point (3) was used to prevent extreme answers and to eliminate the rate of non-responses. Principally, the subjects of the survey were listed companies being traded on the stock exchanges of London, Frankfurt, Madrid, Milan, Paris, Copenhagen, Amsterdam, Zurich, Brussels, Luxemburg and Warsaw. An invitation e-mail was sent to 1.000 companies listed on the above European stock exchanges at the end of June 2011 and in September 2011 a reminder e-mail was sent to the companies. From the returned questionnaires, 100 responses were found to be complete and usable, rendering a response rate of 10 per cent. The majority of the participants in this study were male. The males presented $74.3 \%$ of the respondents, while the females only presented $25.7 \%$ of the data. The average age of participants ranged from 41 to 50 . Regarding the education level, the majority graduated at Bachelor degree level (52\%) compared to Master Degree level $(40 \%)$ and $\mathrm{PhD}$ level (8\%). Participants had an average of 7 to 10 years of professional work experience. Regarding the frequency of XBRL usage, $45 \%$ of the respondents replied that they use XBRL more than $4 \mathrm{~h}$ every day while $28 \%$ answered that they use XBRL 3-4 $\mathrm{h}$ per day and $11 \% 2-3 \mathrm{~h}$ per day. Finally, $8 \%$ makes use of XBRL 1-2 h per day and the last $8 \%$, less than one $h$ per day. Therefore, this sample represents a population with high levels of XBRL knowledge and experience.

\section{RESULTS}

\subsection{Instrument Reliability and Validity}

To empirically examine the constructs theorized in methodology, we applied factor analysis and reliability analysis. The reliability of each item examined using Cronbach's alpha as it is stated to be the most accepted measure for assessing reliability (Chau, 1999). Reliability analysis of the data is addressed from the viewpoint of both the entire construct model and each model variable individually. The overall Cronbach's alpha analysis for TAM2 was 0.913 signifying that the 16 scales are internally consistent with a high degree of reliability. The results of Cronbach's alpha coefficient for 
item analysis by construct range from 0.771 to 0.831 , suggesting again very good internal consistency reliability for each subscale of the sample. Cronbach's alpha value for the Training Costs (TC) of the system was the highest one (0.831), while Output Quality (OQ) was the lowest (0.771). Factor analysis was addressed using Kaiser-Meyer-Olkin (KMO), a measure factor analysis of sampling adequacy confirmatory. The KMO was 0.882 , exceeding the recommended value of 0.6 (Kaiser, 1974). This result indicates that factor analysis is significant and that the construct model will provide distinctive and trustworthy factors. Additionally, Bartlett's Test of Sphericity was 0.000 which indicates that the correlation among variables is strong and therefore suitable for further analysis. Table 1 and $\mathbf{2}$ show reliability and validity results.

\subsection{Hypotheses Test}

The research hypotheses were tested using linear regression analysis. However, the relationships between the variables cannot be tested in a single regression analysis, because the research model includes more than one independent variable. Therefore, two separate regression analyses will be used to test the model fully (Gefen et al., 2000). Table 3 summarizes the regression results. Hypotheses 1, 2 and 4 predict that intention to use XBRL technology would occur if the XBRL user perceived XBRL to be highly useful and easy to use and if the XBRL user had low training costs. The outcome of the first linear regression indicated that the model has a significant fit, since the $\mathrm{R}$ square was 0.652 which explains $65.2 \%$ of the variation of the dependent variable (BI). In addition, the Durbin-Watson score was 2.272 which shows that there is no presence of autocorrelation among variables. The $\mathrm{F}$ statistic in the model was 59.916. Additionally sig. value was 0.000 , at the 0.01 (1\%) confidence level confirming the significant fit of the model. The standardized beta coefficient for the "Perceived Usefulness" measure was positive and significant (beta $=0.647$, p-value<0.01). Thus, hypothesis 1 is supported. This indicates that an increase in Perceived Usefulness positively influences users' Intention to use XBRL. This result indicates that users will use XBRL if they perceive its efficiency and effectiveness with respect to their job. Therefore, XBRL appears to be a useful tool for participant's jobs as it contributes significantly to complete business processes. For "Perceived Ease Of Use" the standardized beta coefficient was positive and significant (beta $=0.195$, p-value<0.05). Hypothesis 2 is supported. The results reveal that Perceived Ease of Use has a significant effect on users' intention to use XBRL. This result confirms that participants found that XBRL is an easy system to learn and use and therefore, it motivates them to use it more.
Table 1. Reliability analysis

\begin{tabular}{lllllll}
\hline Factors & All factors & PU & PEOU & OQ & TC & BI \\
\hline $\begin{array}{l}\text { Cronbach's } \\
\text { alpha }\end{array}$ & 0.913 & 0.812 & 0.822 & 0.771 & 0.831 & 0.825 \\
\hline
\end{tabular}

Table 2. Factor analysis (validity analysis) KMO and Bartlett's test

\begin{tabular}{lll}
\hline $\begin{array}{l}\text { Kaiser-meyer-olkin } \\
\text { measure of sampling adequacy }\end{array}$ & 000,882 \\
$\begin{array}{l}\text { Bartlett's test of sphericity } \\
\text { Chi-square }\end{array}$ & approx. & 873,210 \\
df & 120,000 & \\
Sig. & 000,000 & \\
\hline
\end{tabular}

Table 3. Regression analysis-TAM2-based regression

\begin{tabular}{|c|c|c|c|c|c|c|}
\hline $\begin{array}{l}\text { Independent } \\
\text { variables }\end{array}$ & $\begin{array}{l}\text { Beta } \\
\text { coefficient }\end{array}$ & $\begin{array}{l}\mathrm{p}- \\
\text { value }\end{array}$ & $\mathrm{R}^{2}$ & $\begin{array}{l}\text { Durbin } \\
\text { Watson }\end{array}$ & $\mathrm{F}$ & Sig. \\
\hline \multicolumn{7}{|c|}{ Hypotheses 1, 2, 4} \\
\hline PU 0.647 & 0.000 & 0.652 & 2.272 & 59.916 & 0.000 & \\
\hline PEOU & 0.195 & 0.029 & & & & \\
\hline TC $\quad 0.062$ & 0.310 & & & & & \\
\hline \multicolumn{7}{|c|}{ Dependent variable: BI } \\
\hline PEOU & 0.635 & 0.000 & 0.585 & 2.283 & 64.887 & 0.000 \\
\hline OQ $\quad 0.295$ & 0.000 & & & & & \\
\hline \multicolumn{7}{|c|}{ Dependent variable: PU } \\
\hline
\end{tabular}

Results for "Training Costs" were not statistically significant (beta $=0.062$, p-value $=0.31$ ). Thus, Hypothesis 4 is not supported. This indicates that Training Costs for XBRL are not related with the participant's Intention to use XBRL. This also implies that high training costs have a negative effect on users' intention to use a technology, while low-cost technologies are more attractive to them. Thus, as XBRL demands high training costs, users appear to have a negative reaction on XBRL usage. However, since XBRL is a helpful tool, companies may overcome the implications and problems that arise from such costs.

Hypotheses 3 and 5 predict that Perceived Usefulness of XBRL would occur if the XBRL user perceived XBRL to be easy to use and if the XBRL user is satisfied with the total Output Quality that the XBRL results. Therefore, the higher Output Quality is and the technology easy to use the more likely the user perceives the use of XBRL. The second linear regression indicated that there was $0.585(58,5 \%)$ of the variation of the dependent factor Perceived Usefulness (PU). The Durbin-Watson value for this case was 2,283 which indicate that there is no autocorrelation between variables. Moreover, the analysis of variance displays that the F statistic was 64.887 and sig 0.000 suggesting a 
good model fit. The regression results provide some evidence supporting Hypothesis 3 and 5. Specifically, the standardized beta coefficient for hypothesis 3 was positive and significant (beta $=0.635$, p-value $<0.01$ ). "Perceived Ease Of Use" was making a significant contribution to the prediction of "Perceived Usefulness". PU is more likely to be based on the ease of using a technology. This implies that the users perceive XBRL usefulness, if it helps them work more efficiently and the technology is perceived to be easier than previous existing ways of working. Finally, the standardized path coefficient between Perceived Usefulness and Output Quality was positive and statistically significant (beta $=$ 0.295 , p-value $<0.01)$. PU is considered to be the result of improved job performance and output quality. The user perceives the usefulness of the system when he or she is satisfied with the output quality of the system. This result confirms that XBRL improves the quality of information and increases user's Perceived Usefulness.

\section{DISCUSSION}

$\mathrm{XBRL}$ is an emerging innovation technology based on XML that promises to change the way that financial information is exchanged and presented via internet. XBRL provides great advantages for both users and companies globally as it is an open-source reporting system. The current study provided some empirical evidence supporting four of five hypotheses, which were based on previously validated measurement instruments for technology acceptance. The results reveal that a sizeable number of European companies are satisfied with the output and the perspectives of XBRL usage.

The findings contribute to the existing literature in a number of ways. First, the study makes a contribution to XBRL literature by providing insights into the factors that seem to affect its acceptance. The results reveal that Perceived Usefulness of XBRL is a critical factor influencing XBRL acceptance. This is similar to Pinsker (2008) results, which found that participants perceived XBRL to be useful in their jobs and they had favorable attitudes toward technology in general. Secondly, the results of the first regression analysis indicated that PU has the most significant influence on BI, while PEOU presented relatively low impact regarding the Intention to use XBRL. These findings are consistent with other TAM studies (Davis, 1989; Wu and Wang, 2005; Yi et al., 2006; Van Raaij and Schepers, 2008), which found that PEOU has less impact on technology acceptance than PU. Additionally, Davis (1989) argue that PU is the major determinant of BI. This argument is based on the fact that users will accept a system if they perceive the system to be useful. Moreover, Training Costs were found to have a relatively weak relationship with XBRL acceptance. This finding is in line with another TAM study, examined by $\mathrm{Wu}$ and Wang (2005), which found that cost has the less influence on users' BI than other factors and when there is an emergency or sudden need, the utility benefits of the technology will definitely outweigh the factor of cost. Finally, the findings of the second regression analysis showed that the attributes of PEOU and OQ were both significant and had a strong influence on PU. The results indicate that users are willing to accept and use XBRL if the system is beneficial in helping them in the performance of their work. The above result is consistent with the Hart and Porter (2004) work, which found that the variables PEOU and OQ are positively associated to the dependent variable, PU.

The findings of this study show that the proposed model is appropriate to investigate the acceptance and use of XBRL among European companies. Even though the results can be considered statistically significant in most parts, there are some limitations that have to be mentioned. First of all, even though the sample size was quite large and representative compared to sample sizes of other TAM studies, the number of participants (100) was inconstant, related to the number of the listed European companies (1000). Conceivably, participants may have not been motivated to complete the survey mainly because they were not familiar with the XBRL applications due to the fact that XBRL adoption and acceptance in Europe is at an early stage. The other limitation of the study concerns the determinants of technology acceptance. TAM studies have found that there are other determinants such as: subjective norm, image, job relevant, social influences (Venkatesh and Davis, 2000; Venkatesh et al., 2003) that may affect the Intention to Use and the usage of XBRL. On this basis, the research model might not include possible determinants that affecting the acceptance of XBRL. However, regardless to these limitations this research offers a considerable amount of knowledge in areas such as accounting, reporting and technology systems acceptance.

\section{CONCLUSION}

The main objective of this research is to investigate the acceptance and usage of XBRL across eleven European countries in the light of the Technology Acceptance Model (TAM) added with new variables derived from technology acceptance literature. The 
research highlights XBRL acceptance and usage in the Europe as it indicates that there is a strong user base in Europe supporting and promoting XBRL. According to this, the study is believed to serve as a starting point for the future acceptance of XBRL globally.

As there is limited research related to XBRL acceptance and usage, this study should encourage other researchers to further enrich the current study by adding new possible determinants in the TAM, derived from different sources of literature, that affect the acceptance, use, adoption and evolution of XBRL.

\section{REFERENCES}

Abbasi, M.S., F.H. Chandio, A.F. Soomro and F. Shah, 2011. Social influence, voluntariness, experience and the internet acceptance: An extension of technology acceptance model within a south-Asian country context. J. Enterprise Inform. Manage., 24: 30-52. DOI: $10.1108 / 17410391111097410$

Arnold, V., J.C. Bedard, J.R. Phillips and S.G. Sutton, 2012. The impact of tagging qualitative financial information on investor decision making: Implications for XBRL. Int. J. Account. Inform. Syst., 13: 2-20. DOI: 10.1016/j.accinf.2011.12.002

Baldwin, A.A., C.E. Brown and B.S Trinkle, 2006. XBRL: An impacts framework and research challenge. J. Emerg. Technol. Accoun., 3: 97-116. DOI: $10.2308 /$ jeta.2006.3.1.97

Basoglou, N., T. Daim and O. Kerimoglu, 2007. Organizational adoption of enterprise resource planning systems: A conceptual framework. J. High Technol. Manage. Res., 18: 73-97. DOI: 10.1016/j.hitech.2007.03.005

Blanas, G., A. Stavropoulos and E. Stergiaki, 2011. XBRL passport: A pilot model for web financial reporting in the greek capital market. Proceedings of the Management of International Business and Economics Systems, Sept. 16-18, IEEE Xplore Press, Greece, pp: 100-121.

Bonson, E., Cortijo, V. and T. Escobar, 2009. Towards the global adoption of XBRL using International Financial Reporting Standards (IFRS). Int. J. Account. Inform. Syst., 10: 46-60. DOI: 10.1016/j.accinf.2008.10.002

Buys, P.W., 2008. The impact of XBRL on the financial reporting supply chain: A South African case study. Meditari Accoun. Res., 16: 43-58. DOI: 10.1108/10222529200800003

Castaneda, J.A., D.M. Frias and M.A. Rodriguez, 2009. Antecedents of internet acceptance and use as an information source by tourists. Online Inform. Rev., 33: 548-567. DOI: 10.1108/14684520910969952
Chau, P., 1999. On the use of construct reliability in MIS research: A meta-analysis. Inform. Manage., 35: 217-227. DOI: 10.1016/S0378-7206(98)00089-5

Chen, L., M.L. Gillenson and D.L. Sherrell, 2002. Enticing online consumers: An extended technology acceptance perspective. Inform. Manage., 39: 705719. DOI: 10.1016/S0378-7206(01)00127-6

Davis, F.D., 1989. Perceived usefulness, perceived ease of use and user acceptance of information technology. MIS Q., 13: 319-340. DOI: $10.2307 / 249008$

Dishaw, M.T. and D.M. Strong, 1999. Extending the technology acceptance model with task-technology fit constructs. Inform. Manage., 36: 9-21. DOI: 10.1016/S0378-7206(98)00101-3

Doolin, B. and I. Troshani, 2007. Organizational adoption of XBRL. Electr. Mark., 17: 199-209. DOI: $10.1080 / 10196780701503195$

Felden, C., 2011. Characteristics of XBRL adoption in Germany. J. Manage. Control, 22: 161-186. DOI: 10.1007/s00187-011-0134-7

Gefen, D., D.W. Straub and M. Boudreau, 2000. Structural equation modeling and regression: Guidelines for research practice. Commun. Assoc. Inform. Syst., 4: 1-79.

Ghani, E.K. and K. Jusoff, 2009. Determinants of preferred financial digital format by New Zealand accounting practitioners. Int. Educ. Stud., 2: 167-177.

Graning, A., C. Felden and M. Piechocki, 2011. Status quo and potential of XBRL for business and information systems engineering. Bus. Inform. Syst. Eng., 3: 231-239. DOI: 10.1007/s12599-011-0169-1

Hart, M. and G. Porter, 2004. The impact of cognitive and other factors on the perceived usefulness of OLAP. J. Comput. Inform. Syst., 45: 47-56.

Henderson, D., S.D. Sheetz and B.S. Trinkle, 2012. The determinants of inter-organizational and internal inhouse adoption of XBRL: A structural equation model. Int. J. Account. Inform. Syst., 13: 109-140. DOI: $10.1016 /$ j.accinf.2012.02.001

Hill, R.S. and I. Troshani, 2007. A conceptual framework and propositions for the acceptance of mobile services. J. Theoretical Applied Electr. Commerce Res., 2: 61-73.

Hodge, F., J.J Kennedy and L. Maines, 2004. Does search-facilitating technology improve the transparency of financial reporting? Accoun. Rev., 79: 687-703. DOI: 10.2307/3203275

Hossain, L. and A. De Silva, 2009. Exploring user acceptance of technology using social networks. J. High Technol. Manage. Res., 20: 1-18. DOI: 10.1016/j.hitech.2009.02.005 
Kaiser, H., 1974. An index of factorial simplicity. Psychometrika, 39: 31-36. DOI: 10.1007/BF02291575

Locke, J. and A.D. Lowe, 2007. Researching XBRL as a Socio-Technical Object. In: New Dimensions of Business Reporting and XBRL, Debreceny, R., C. Felden and M. Piechocki (Eds.), Springer, Wiesbaden, ISBN-10: 3835008358, pp: 271-271.

Pinsker, R., 2008. An empirical examination of competing theories to explain continuous disclosure technology adoption intentions using XBRL as the example technology. Int. J. Digital Account. Res., 8: 81-96. DOI: 10.4192/1577-8517-v8_4

Premuroso, R. and S. Bhattacharya, 2007. Do early and voluntary filers of financial information in XBRL format signal superior corporate governance and operating performance? Int. J. Account. Inform. Syst., 16: 58-78. DOI: 10.1016/j.accinf.2008.01.002

Saeedi, A., J. Richards and B. Smith, 2005. An Introduction to XBRL. Irainan Account. Audit. Rev., 45: 132-158. DOI: 10.2139/ssrn. 1007570

Valentinetti, D. and M.A. Rea, 2011. Adopting XBRL in Italy: Early evidence of fit between Italian GAAP Taxonomy and current reporting practices of nonlisted companies. Int. J. Digital Account. Res.

Van Raaij, E.M. and J.J.L. Schepers, 2008. The acceptance and use of a virtual learning environment in China. Comput. Educ., 50: 838-852. DOI: 10.1016/j.compedu.2006.09.001
Venkatesh, V. and F.D. Davis, 2000. A theoretical extension of the technology acceptance model: Four longitudinal field Studies. Manage. Sci., 46: 186204. DOI: $10.1287 / \mathrm{mnsc} .46 .2 .186 .11926$

Venkatesh, V., M.G. Morris, G.B. Davis and F.D. Davis, 2003. User acceptance of information technology: Toward a unified view. MIS Q., 27: 425-478.

Wang, R. and D. Strong, 1996. Beyond accuracy: What data quality means to data consumers. J. Manage. Inform. Syst., 12: 5-33.

Weber, RA., 2003. XML, XBRL and the Future of Business and Business Reporting. In: Trust and Data Assurances in Capital Markets: The Role of Technology Solutions. Roohani, S.T., (Eds.), Smithfield, Smithfield, Rhode Island, USA., pp: 3-4.

$\mathrm{Wu}$, J.H. and S.C. Wang, 2005. What drives mobile commerce?: An empirical evaluation of the revised technology acceptance model. Inform. Manage., 42: 719-729. DOI: 10.1016/j.im.2004.07.001

Yi, M.Y., J.D. Jackson, J.S. Park and J.C. Probst, 2006. Understanding information technology acceptance by individual professionals: Toward an integrative view. Inform. Manage., 43: 350-363. DOI: 10.1016/j.im.2005.08.006

Youngberg, E., D. Olsen and K. Hauser, 2009. Determinants of professionally autonomous end user acceptance in an enterprise resource planning system environment. Int. J. Inform. Manage., 29: 138-144. DOI: 10.1016/j.ijinfomgt.2008.06.001 